OPEN ACCESS

Edited by:

Elvira Forte,

Jackson Laboratory, United States

Reviewed by:

Debora Lo Furno,

Università di Catania, Italy

Stefano Ministrini,

University of Zurich, Switzerland

*Correspondence:

Edwin Leong

edwinleong@dal.ca

Specialty section:

This article was submitted to

Integrative Physiology,

a section of the journal

Frontiers in Physiology

Received: 18 June 2021 Accepted: 09 August 2021

Published: 27 August 2021

Citation:

Leong E, Bezuhly M and Marshall JS (2021) Distinct

Metalloproteinase Expression and Functions in Systemic Sclerosis and Fibrosis: What We Know

and the Potential for Intervention.

Front. Physiol. 12:727451

doi: 10.3389/fphys.2021.727451

\section{Distinct Metalloproteinase Expression and Functions in Systemic Sclerosis and Fibrosis: What We Know and the Potential for Intervention}

\author{
Edwin Leong ${ }^{1 *}$, Michael Bezuhly ${ }^{2,3}$ and Jean S. Marshall ${ }^{1,2}$ \\ 'Department of Pathology, Dalhousie University, Halifax, NS, Canada, ${ }^{2}$ Department of Microbiology and Immunology, \\ Dalhousie University, Halifax, NS, Canada, ${ }^{3}$ Department of Surgery, Dalhousie University, Halifax, NS, Canada
}

Systemic sclerosis (SSc) is a chronic debilitating idiopathic disorder, characterized by deposition of excessive extracellular matrix (ECM) proteins such as collagen which leads to fibrosis of the skin and other internal organs. During normal tissue repair and remodeling, the accumulation and turnover of ECM proteins are tightly regulated by the interaction of matrix metalloproteinases (MMPs) and endogenous tissue inhibitors of metalloproteinases (TIMPS). SSc is associated with dysregulation of the activity of these proteolytic and inhibitory proteins within the tissue microenvironment, tipping the balance toward fibrosis. The resultant ECM accumulation further perpetuates tissue stiffness and decreased function, contributing to poor clinical outcomes. Understanding the expression and function of these endogenous enzymes and inhibitors within specific tissues is therefore critical to the development of therapies for SSc. This brief review describes recent advances in our understanding of the functions and mechanisms of ECM remodeling by metalloproteinases and their inhibitors in the skin and lungs affected in SSc. It highlights recent progress on potential candidates for intervention and therapeutic approaches for treating SSc fibrosis.

Keywords: fibrosis, systemic sclerosis, metalloproteinase, skin, lung, tissue inhibitors of metalloproteinase, inflammation

\section{INTRODUCTION}

Systemic sclerosis (SSc) is a complex chronic disease of unknown etiology, with external environmental factors, genetic predisposition, and epigenetic changes implicated in its development (Mora, 2009; Ramos et al., 2015; Angiolilli et al., 2018). SSc is characterized by persistent immune system activation, changes in vascularization, and excessive extracellular matrix (ECM) accumulation leading to fibrosis. There is considerable heterogeneity of clinical presentations in SSc patients, ranging from Raynaud's phenomenon to severe fibrosis affecting critical organ function in severe cases (Sunderkötter and Riemekasten, 2006; Allanore et al., 2015; Varga et al., 2017). SSc can be classified as "limited" or "diffuse," depending on the extent and progression of disease in the skin, with the latter involving more proximal skin locations and having increased impact on internal organ systems (Sobolewski et al., 2019). Uncontrolled fibrosis can 
impair organ function to the point of failure and even death (Varga and Abraham, 2007). Current treatments for SSc are limited with variable clinical response (Allanore et al., 2016; Kowal-Bielecka et al., 2017; Varga et al., 2017), and emerging therapeutics target fundamental fibrotic processes associated with SSc (Daoussis and Liossis, 2019). Metalloproteinases and their regulators play pivotal roles in mediating fibrosis, making them attractive therapeutic targets in SSc. Given their function in homeostasis, a thorough understanding of their roles in healthy and fibrotic tissues is required to develop safe and effective therapies targeting these pathways.

\section{EXTRACELLULAR MATRIX AND ROLES IN FIBROSIS}

Early changes in ECM may provide means for better diagnostic accuracy in fibrotic disease (Abignano and Del Galdo, 2014; Burgstaller et al., 2017). However, clinical disease is often well established prior to diagnosis, reducing opportunities for early intervention. Increased ECM accumulation and matrix stiffness decreases tissue function, promoting further damage and perpetuating fibrosis (Lampi and Reinhart-King, 2018; Santos and Lagares, 2018). ECM accumulation and stiffness relay mechanical cues, initiate mechanosensory responses (Herrera et al., 2018; Tschumperlin et al., 2018), and provide major reservoirs for latent TGF- $\beta$ (Annes et al., 2003; Xu et al., 2018) that is activated by conformational changes to further promote pro-fibrotic processes (Annes et al., 2004; Wipff et al., 2007). Myofibroblasts, a major source of ECM proteins, receive sustained survival and differentiation signals from matrix stiffness (Lagares et al., 2017; Van Caam et al., 2018). Further consequences include reduced nutrient diffusion, hypoxia, and epigenetic modifications of local cell populations (Beyer et al., 2009; Liu et al., 2010; Parker et al., 2014). These can change myofibroblast phenotypes by inducing transcription factor activity (Dupont et al., 2011; Dupont, 2019), specific microRNAs, and DNA methylation processes causing sustained cellular activation independent of the initial insult (Orphanides et al., 1997; Corpechot, 2002; Wang et al., 2006; Altorok et al., 2015). Together, these interactions drive multiple amplifying loops, further promoting cellular activation and enhanced ECM deposition (Figure 1). Thus, matrix stiffness caused by ECM accumulation needs to be tightly regulated to allow normal tissue remodeling and prevent pathologic fibrosis.

\section{MATRIX METALLOPROTEINASES AND THEIR INHIBITORS}

Matrix stiffness is determined by a balance between ECM breakdown and accumulation, with the latter more significant in SSc (Varga and Bashey, 1995). Two main classes of mediators involved in this balance are matrix metalloproteinases (MMPs) and tissue inhibitors of metalloproteinases (TIMPs) (Nagase et al., 2006). Currently, there are 24 known MMPs in humans which are categorized based on their preferred substrates such as collagenases (MMP1, 8, 13) and gelatinases (MMP2, MMP9) (Loffek et al., 2011). TIMPs are the natural inhibitors of MMPs and classically inhibit ECM degradation (Brew and Nagase, 2010).

Current disease models suggest that increasing active MMPs and downregulating TIMPs would be beneficial to facilitate proper tissue remodeling and restoration of tissue homeostasis; however, MMPs and TIMPs have physiological implications beyond tissue remodeling (Giannandrea and Parks, 2014) including facilitating inflammation through cellular trafficking, immune cell activation, regulation of cytokines, chemokines, and activity of other MMPs (Nagase et al., 2006; Gaffney et al., 2015). The expression of MMPs is also cell- and tissue-specific and temporally regulated by immune and stromal cells, further adding to the complexity of this system (Pardo and Selman, 2006; Chuang et al., 2019). Finally, MMP functions depend on tissue and disease context (Loffek et al., 2011), and have both pro- and anti-fibrotic effects. To this end, global upregulation of MMPs and downregulation of TIMPs is ineffective in overcoming excessive ECM accumulation. Manipulation of this system requires an understanding of interactions between expressed MMPs and TIMPs within specific organs at specific stages of disease progression to be effective.

\section{METALLOPROTEINASES IN SSc SERUM}

Analysis of specific MMPs and TIMPs in the serum of SSc patients suggests possible influences on outcomes in different tissues. MMP7 was increased in SSc patients with considerably higher levels of observable lung fibrosis compared to healthy individuals (Moinzadeh et al., 2011). In contrast, MMP13 was reduced in serum from local and diffuse SSc patients compared to normal controls, with reductions reflecting greater tissue involvement and lung fibrosis (Asano et al., 2006a,b). Adding to the complexity, MMP9 was found increased in serum and tears of SSc patients along with increased TIMP-2, supporting a negative role for these mediators (Waszczykowska et al., 2020). Autoantibodies against MMP3 have been detected in SSc patients, and MMP3 considered beneficial as inhibition is suggested to reduce ECM degradation (Nishijima et al., 2004). It is evident that distinct MMPs may have multifaceted roles in ECM turnover and while MMP-TIMP expression in serum samples serve as potential biomarkers of SSc prognosis, involvement in organ fibrosis is likely far more complex than data on general upregulation or downregulation might suggest.

\section{METALLOPROTEINASES IN SKIN FIBROSIS}

The MMP profile in skin tissue is limited and while well-studied in skin pathologies such as wound healing (Kähäri and SaarialhoKere, 1997; Caley et al., 2015; Nguyen et al., 2016), less is known about their roles in fibrotic cutaneous disorders such as SSc. Skin involvement is present in both milder and severe forms of SSc and there is increased ECM deposition in the skin during fibrosis 


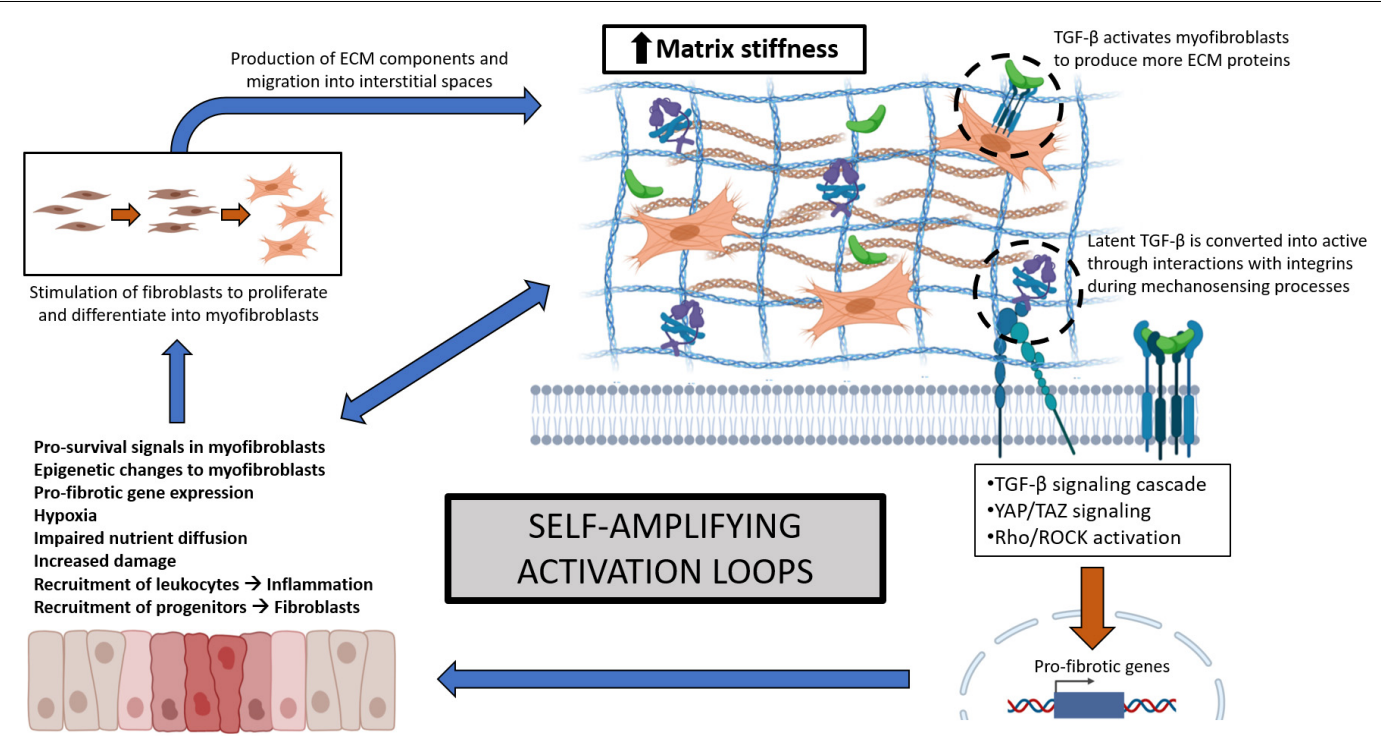

FIGURE 1 | Self-amplifying activation loops involving multiple signaling elements during fibrosis, resulting from increased ECM accumulation and matrix stiffness. Increased tissue stiffness leads to reduced function, hypoxia, and triggers mechanosensory-related transcription factors, causing more damage, pro-fibrotic gene expression, and fibroblast activation and differentiation into myofibroblasts. Myofibroblasts contribute to ECM synthesis and accumulation and are supported by pro-survival signals and epigenetic changes to further enhance fibrosis. These self-amplifying mechanisms are conserved across different organ fibroses.

progression. A positive correlation is observed between presence of abnormal subtypes of collagen with disease stage and dermal thickness scores (Martin et al., 2012).

Significantly reduced levels of interstitial collagenase MMP1 expression have been found in biopsies of involved skin in a cohort of SSc patients (Frost et al., 2012). This was corroborated by other studies showing markedly reduced MMP1 gene expression and protein levels in dermal fibroblasts isolated from SSc patient skin. Several microRNAs increased in serum and skin of SSc patients were observed to downregulate MMP1 expression (Sing et al., 2012; Zhou et al., 2017). Peripheral blood mononuclear cells from SSc patients produced cytokines and growth factors in response to soluble type 1 collagen in vitro that elicited reduced MMP1 production by SSc dermal fibroblasts (Brown et al., 2012), pointing to additional forms of MMP1 regulation. CXCL17, a chemokine implicated in several tissue remodeling and antimicrobial processes, was found reduced in SSc skin and can regulate type 1 collagen expression by MMP1associated mechanisms (Shimada et al., 2020). Local CXCL17 injections ameliorated fibrotic outcomes in a murine model of bleomycin (BLM)-induced skin fibrosis and CXCL17 treatment reduced type 1 collagen protein while increasing gene and protein expression of MMP1 in healthy human dermal fibroblasts.

MMP3, crucial for inhibition of pro-fibrotic $\alpha 2$-antiplasmin and ECM deposition, was decreased in SSc fibroblasts (Niwa et al., 2020). MMP3-stimulated SSc fibroblasts decreased $\alpha$-SMA expression and type 1 collagen production. Given that collagenases function to breakdown ECM materials, in theory increasing skin-specific MMPs and reducing TIMPs should ameliorate fibrosis. However, this is not always the case. Increased MMP9 production was found in SSc patient dermal fibroblasts, positively correlating with the extent of SSc skin pathology
(Kim et al., 2005) and likely due to MMP9 activities independent of ECM degradation, including regulation of inflammatory cytokines and growth factors (Van Den Steen et al., 2002). MMP9 degrades ECM but also other important non-cellular components that maintain effective barriers within the SSc skin microenvironment. A combination of barrier dysfunction and enhanced inflammatory and pro-fibrotic growth factors can enable an influx of immune cells, perpetuating inflammation and established fibrosis (Yu and Stamenkovic, 2000; Kim et al., 2005).

Along with dysregulation of MMPs, TIMPs are reported to be elevated in SSc skin. Fibroblasts derived from SSc biopsies demonstrated increased TIMP-1 compared to those from control skin (Kikuchi et al., 1997). Thus, reducing production of this inhibitor may be beneficial in SSc. The production of TIMP1 by SSc dermal fibroblasts was reduced when treated with microRNA-29a, associated with increased MMP1 production (Ciechomska et al., 2014). Taken together, modulating the MMP-TIMP balance could potentially reverse the SSc fibroblast phenotype and offer therapeutic opportunities for treatment of skin fibrosis. However, considering the complex expression patterns of metalloproteinases and inhibitors in SSc patient skin, anti-fibrotic strategies involving ECM degradation by MMPs require further clinical study.

In non-SSc fibrotic conditions such as hypertrophic scarring, MMP3 and MMP8 are increased with TIMP members while other classical MMPs decreased. Several MMP-deficient strains of mice have been reported to have little change in phenotype, pointing toward functional redundancy between members of this family (Loffek et al., 2011). However, skin wound healing studies have shown MMP13 promotes rapid collagen remodeling and fibroblast survival, resulting in effective and scarless healing (Toriseva et al., 2007). MMP14-deficient mice demonstrate 
insufficient collagen turnover leading to connective tissue pathologies (Holmbeck et al., 1999), indicating that functions of MMP14 may not be readily compensated for by others. Using the BLM-induced skin fibrosis model (Yamamoto et al., 1999), MMP14-deficient mice exhibited significant accumulation of type 1 collagen in the skin but without changes to collagen synthesis (Zigrino et al., 2016), and fibroblasts from their skin showed impaired MMP2 activation. Therefore, MMP14 may be particularly important in degrading dermal ECM components and regulation of other MMPs. Taken together, these studies support studying these MMPs as targets for therapy in SSc skin.

\section{METALLOPROTEINASES IN LUNG FIBROSIS}

The lungs are a major affected organ, where SSc manifests as interstitial lung disease (ILD) characterized by extensive fibrosis, leading to decreased functional capacity and even death (Cottin and Brown, 2019). Aberrant expression of MMPs have been reported, but with functions seemingly contrary to their classical ECM proteolytic activities. In multiple studies, elevated MMP7 serum levels have shown a negative correlation with lung function parameters such as forced vital capacity and associated with advanced stages of SSc. These observations suggest that MMP7 may, directly or indirectly, contribute to lung fibrosis, and may serve as a biomarker for SSc progression (Moinzadeh et al., 2011; Stock et al., 2019; Abo Gabal et al., 2020). In bronchoalveolar lavage fluid (BALF) of SSc patients with ILD, MMP9 levels were elevated compared to healthy controls, suggesting involvement in the persistence of inflammatory processes (Andersen et al., 2007). MMP12 is increased in serum and lung tissues of SSc patients with ILD and positively correlates with lung fibrosis severity. MMP12 expression was abundant in regions of thickened alveolar septa and expressed by alveolar macrophages and fibroblasts residing in fibrotic lung compartments (Manetti et al., 2012). A specific MMP12 polymorphism was also found to increase susceptibility to SSc and ILD in a cohort of SSc patients compared to healthy individuals (Manetti et al., 2010; Assassi et al., 2013). While MMP12 functions in SSc-ILD have not been defined, MMP12 downregulated expression of collagenase MMP13 in a Schistosoma mansoni Th2-driven model of lung fibrosis (Madala et al., 2010), providing a crucial example of MMP-dependent regulation of other metalloproteinases. Notably, serum MMP13 levels were lower in a subset of SSc patients compared to healthy controls, and reductions associated with significantly greater frequency of reduced vital capacity (Asano et al., 2006b). This suggests that MMP13 is associated with ECM remodeling and deficiency enhances lung fibrosis.

Matrix metalloproteinases have also been examined in idiopathic lung fibrosis (IPF) - another debilitating form of lung pathology arising from aberrant ECM deposition and remodeling. While there are differences between SSc-ILD and IPF, there are notable similarities particularly during the endstages of the diseases (Herzog et al., 2014). These include signaling arising from injurious stimuli leading to pro-fibrotic events, and a pro-fibrotic phenotypic shift of pulmonary fibroblasts in response to ECM composition containing collagen, tenascin- $\mathrm{C}$, and mechanical cues resulting from increased tissue stiffness (Brissett et al., 2012; Herzog et al., 2014).

Idiopathic lung fibrosis patient BALF show increased expression of MMPs, with MMP7, MMP8, and MMP9 predominating (Dancer et al., 2011). MMP7 is highly upregulated and activated in IPF patient lungs (Zuo et al., 2002; Fujishima et al., 2010), and is the most upregulated gene encoding for proteins involved in ECM remodeling. MMP7 can promote fibrosis in the early phases by inducing epithelial cell damage but have immunosuppressive and anti-fibrotic potential in persistent fibrotic lung environments in longer-term studies in MMP7deficient animals (Li et al., 2002; Zuo et al., 2002; Manicone et al., 2009), highlighting disease stage influence on MMP7 involvement. MMP8 can act indirectly to enhance lung fibrosis by cleaving anti-inflammatory IL-10, an inhibitor of TGF- $\beta$, maintaining a pro-fibrotic environment (García-Prieto et al., 2010). Increased MMP8 expression was found in IPF patient BALF (Henry et al., 2002; Stijn et al., 2013; Craig et al., 2014) and others have shown MMP8 associated with significant reductions in CXCL10, reported to be anti-fibrotic in lungs (Marie Burdick et al., 1999; Tager et al., 2004; Jiang et al., 2010) by inhibiting lung fibroblast migration and differentiation into myofibroblasts (Craig et al., 2013). MMP3 is upregulated in IPF patients compared to healthy control lungs (Yamashita et al., 2011). MMP3-deficient mice exhibited reduced fibrosis in response to BLM and exogenous recombinant MMP3 promoted pro-fibrotic phenotypes. Further assessments found correlations between increased MMP3 and a collagenolytic by-product endostatin (Heljasvaara et al., 2005), which induces lung epithelial cell apoptosis (Richter et al., 2009) and thus promotes fibrosis.

Despite having pro-fibrotic roles in lungs as described above, specific MMPs show anti-fibrotic functions. Contrary to SSc-ILD, active MMP13 is increased in whole lung samples of IPF patients (Nkyimbeng et al., 2013). In IPF rodent models, MMP13deficiency demonstrated exacerbated inflammatory responses to lung injury (Sen et al., 2010) and BLM-induced lung fibrosis, associated with increased leukocytic infiltration such as neutrophils (Nkyimbeng et al., 2013) and macrophages (Cabrera et al., 2019). Additionally, MMP13-deficient lung tissues had higher collagen staining and hydroxyproline content. Others showed MMP13-deficient mice having delayed resolution of lung fibrosis through decreased collagenolytic activity (Cabrera et al., 2019). Similarly, MMP19 is increased in IPF patients, and considered indicative of a tissue repair response (Yu et al., 2012). MMP19-deficient mice showed increased $\alpha$-SMA staining and collagen deposition, possibly exerting its anti-fibrotic effects by mediating expression of cyclo-oxygenase 2 to suppress fibrosis by regulation of fibroblast proliferation and collagen synthesis (Wilborn et al., 1995; Pomianowska et al., 2014; Zhao et al., 2016). Thus, MMP19 may be an important anti-fibrotic metalloproteinase in the lungs through regulation of ECM deposition. MMP9 is classically pro-fibrotic (Kobayashi et al., 2014) and is increased in IPF patient BALF (Henry et al., 2002). However, significant anti-fibrotic activity was shown in a mouse model overexpressing human MMP9 in alveolar macrophages (Cabrera et al., 2007), potentially linked to inhibition of fibroblast 
growth (Valentinis et al., 1995). Appropriate regulation of cell growth, repair, and apoptosis were proposed to ameliorate the lung fibrosis in this model.

\section{MMPS IN OTHER SSC-ASSOCIATED ORGAN SYSTEMS}

While cardiac, gastrointestinal (GI), and renal organ systems are involved in SSc, MMPs have not been directly studied in such clinical tissues. SSc cardiac complications range from ventricular dysfunction to infarction (Lambova, 2014), resulting in tissue damage and ensuing fibrosis (Tzelepis et al., 2007). In murine models, MMP-1 attenuated cardiac fibrosis development (Foronjy et al., 2008), but MMP-2 promoted ventricular remodeling, leading to failure-associated phenotypes (Bergman et al., 2007). MMP-12 induced production of TGF- $\beta$ and plateletderived growth factor, promoting accumulation of macrophage populations involved in fibrotic mechanisms (Stawski et al., 2014). GI manifestations are common in SSc patients, which can lead to fibrosis and ensuing motility and functional aberrations (Sallam et al., 2006; McFarlane et al., 2018). GI MMPs have not been directly studied in SSc, but have important functions in several intestinal inflammatory disorders (Medina and Radomski, 2006; O'Sullivan et al., 2015). While many point toward detrimental MMP functions during inflammation, one study has shown inhibited MMP synthesis can lead to excessive collagen deposition in fibrotic intestinal muscles (Bailey et al., 2012). Kidney involvement is also prevalent in SSc patients, leading to scleroderma renal crisis (SRC), promoted by interstitial fibrosis amongst other risk factors (Steen, 2014; Chrabaszcz et al., 2020). Direct MMP involvement in SSc-associated renal fibrosis has not been identified, but numerous studies imply a detrimental role of MMPs in early stages of kidney diseases with ECM-degradative features in later stages during scarring and fibrosis (Ke et al., 2017; Zakiyanov et al., 2019). Upregulated peptides in renal pathologies such as angiotensin-II promote renal fibrosis and regulate MMP expression, further affecting remodeling processes (Solini et al., 2011; Pushpakumar et al., 2013).

\section{MMPS AS THERAPEUTIC TARGETS FOR FIBROSIS AND SSC: WHERE ARE WE CURRENTLY?}

As outlined above, MMPs demonstrate tissue-dependent and disease-specific expression and functions (summarized in Table 1). Clinical translation of broad-spectrum MMP inhibitors

TABLE 1 | Summary table of selected MMPs with therapeutic potential for targeting in SSc skin and lungs to improve fibrosis and ECM accumulation.

\begin{tabular}{|c|c|c|}
\hline MMP & Skin & Possible function / mechanism in the skin \\
\hline Mmp1 & SSc & Decreased; Collagen breakdown Frost et al. (2012); Sing et al. (2012); Zhou et al. (2017) \\
\hline Mmp3 & SSc & Decreased; Decreased $\alpha$-SMA and type 1 collagen production Niwa et al. (2020) \\
\hline Mmp9 & SSc & $\begin{array}{l}\text { Increased; Regulation of inflammatory cytokines and growth factors; Degrades non-cellular components of the skin barrier, leading } \\
\text { to increased infiltration of inflammatory cell Kim et al. (2005) }\end{array}$ \\
\hline Mmp13 & Wound healing & Rapid collagen remodeling Toriseva et al. (2007) \\
\hline Mmp14 & $\begin{array}{l}\text { BLM-induced } \\
\text { skin fibrosis }\end{array}$ & $\begin{array}{l}\text { Knockouts show significant type } 1 \text { collagen accumulation in skin, and impaired Mmp2 activation Holmbeck et al. (1999); Zigrino } \\
\text { et al. (2016) }\end{array}$ \\
\hline MMP & Lung & Possible function / mechanism in the lungs \\
\hline Mmp3 & IPF & $\begin{array}{l}\text { Increased and produces endostatin, a by-product that increases lung epithelial cell death; Knockout mice have less lung fibrosis } \\
\text { Heljasvaara et al. (2005); Richter et al. (2009); Yamashita et al. (2011) }\end{array}$ \\
\hline \multirow[t]{2}{*}{ Mmp7 } & SSC-ILD & Increased; Not defined Moinzadeh et al. (2011); Stock et al. (2019); Abo Gabal et al. (2020) \\
\hline & IPF & $\begin{array}{l}\text { Increased in BALF; Associated with epithelial cell damage and neutrophil recruitment in early stages, but associated with } \\
\text { immunosuppressive dendritic cell recruitment in late stages Li et al. (2002); Zuo et al. (2002); Manicone et al. (2009); Fujishima et al. } \\
\text { (2010) }\end{array}$ \\
\hline Mmp8 & IPF & $\begin{array}{l}\text { Increased in BALF; Cleaves IL-10, a suppressor of TGF- } \beta \text { synthesis; decreased CXCL10 Wilborn et al. (1995); Henry et al. (2002); } \\
\text { Tager et al. (2004); García-Prieto et al. (2010); Jiang et al. (2010); Dancer et al. (2011); Craig et al. (2013, 2014); Stijn et al. (2013) }\end{array}$ \\
\hline \multirow[t]{2}{*}{ Mmp9 } & SSc-ILD & Increased; Involved in persistence of inflammatory processes Andersen et al. (2007); Dancer et al. (2011) \\
\hline & IPF & $\begin{array}{l}\text { Increased in BALF; Overexpression in alveolar macrophages in mice showed anti-fibrotic activity via regulation of fibroblast growth } \\
\text { Valentinis et al. (1995); Henry et al. (2002); Cabrera et al. (2007); Kobayashi et al. (2014) }\end{array}$ \\
\hline \multirow[t]{2}{*}{ Mmp12 } & SSc-ILD & Increased; Not defined Manetti et al. (2010, 2012); Assassi et al. (2013) \\
\hline & $\begin{array}{l}\text { Schistosoma } \\
\text { mansoni lung } \\
\text { fibrosis }\end{array}$ & Knockouts show increased fibrosis and decreased Mmp13 collagenase Madala et al. (2010) \\
\hline Mmp13 & IPF & $\begin{array}{l}\text { Increased in whole lung; Knockouts have decreased collagenolytic activity and higher collagen levels Asano et al. (2006a); Sen et al. } \\
\text { (2010); Nkyimbeng et al. (2013); Cabrera et al. (2019) }\end{array}$ \\
\hline Mmp19 & IPF & $\begin{array}{l}\text { Increased in IPF patients, but indicative of tissue repair; Knockouts show increased collagen deposition, and may act through } \\
\text { regulation of cyclo-oxygenase } 2 \text { expression Wilborn et al. (1995); Yu et al. (2012); Pomianowska et al. (2014); Zhao et al. (2016) }\end{array}$ \\
\hline
\end{tabular}

Described roles in other similar types of pathology and disease are also given, with mechanisms that may be translatable to SSc pathology in the skin and lungs. 
(MMPIs) have been largely unsuccessful despite success in some experimental models (de Meijer et al., 2010), likely due to beneficial MMP functions in homeostasis and immunity (Vandenbroucke and Libert, 2014). This is evidenced by discontinuation of poorly selective MMPIs in anti-cancer clinical trials due to adverse responses (Fields, 2019) and lack of MMPbased trials in SSc-ILD (Khanna et al., 2019). Cross-regulation of MMP members further add to the unpredictable impact of MMPIs. Novel methods for targeting metalloproteinases are necessary, with increased specificity and localized delivery to fibrotic sites. Developing selective synthetic peptides to block catalytic functions, targeting unique MMP domains to alter function, or manipulating endogenous MMP regulators like microRNAs represent some potential avenues of investigation (Li and Li, 2013; Mohan et al., 2016), serving as basis for novel proposed clinical trials in SSc skin (ClinicalTrials.gov identifier \#NCT03740724). New treatment modalities should consider temporal regulation of MMPs and stages of disease in which they are active. Together, new classes of MMPIs with improved disease models will help our understanding of MMP profiles observed in fibrotic conditions such as in SSc.

From what is currently known regarding MMPs in skin and lungs of SSc patients, there are likely two main functions of MMPs, first as mediators of inflammation and tissue damage, and second as contributors to ECM remodeling. As previously mentioned, collagenases like MMP1 and MMP3 are reduced in settings of greater SSc skin fibrosis, and experimental models suggest that increasing their levels or activity may have beneficial effects. Conversely, inhibiting others like MMP9 could be beneficial to ameliorate pro-inflammatory triggers of SSc progression. The functions of MMP13 and MMP14 in promoting wound healing may also warrant further investigation in the context of SSc. In SSc-ILD, MMP7, 8, 9, and 12 seem to primarily exacerbate the disease rather than degrade ECM and may justify targeting them for local inhibition. Temporally regulating MMP expression or activity during different disease stages has merit, as demonstrated in the delayed resolution of IPF in MMP13deficient. Future research should involve detailed human studies which consider disease stage and tissue site when examining the

\section{REFERENCES}

Abignano, G., and Del Galdo, F. (2014). Quantitating skin fibrosis: innovative strategies and their clinical implications topical collection on scleroderma. Curr. Rheumatol. Rep. 16:404.

Abo Gabal, M. M., Shedid, N. H., Mohamed, E. S., Abdelfattah, W., and Mohamed, S. (2020). The relationship between serum level of matrix metalloproteinase-7 and interstitial lung disease in patients with systemic sclerosis. Egypt. J. Intern. Med. 314, 720-725.

Allanore, Y., Matucci-Cerinic, M., and Distler, O. (2016). Treatment of systemic sclerosis: is there any hope for the future? RMD Open 2:e000260. doi: 10.1136/ rmdopen-2016-000260

Allanore, Y., Simms, R., Distler, O., Trojanowska, M., Pope, J., Denton, C. P., et al. (2015). Systemic sclerosis. Nat. Rev. Dis. Primers 1:15002.

Altorok, N., Tsou, P. S., Coit, P., Khanna, D., and Sawalha, A. H. (2015). Genome-wide DNA methylation analysis in dermal fibroblasts from patients with diffuse and limited systemic sclerosis reveals common and subset-specific DNA methylation aberrancies. Ann. Rheum. Dis. 74, 1612-1620. doi: 10.1136/ annrheumdis-2014-205303 activities of specific MMPs. Without such information, there is a considerable risk of off-target effects of targeting MMPs.

\section{CONCLUDING REMARKS}

Currently, therapeutics targeting regulation of MMP-TIMP balance in SSc have not successfully translated into clinical settings despite considerable effectiveness in pre-clinical models, with a lack of ongoing clinical trials. From previous and current studies, it is evident that MMPs and TIMPs have multiple roles which may either promote or inhibit fibrosis. Moreover, the complex cross-regulation of these molecules necessitates looking at the MMP-TIMP axis as a network rather than individually in the context of disease. The expression of MMPs and TIMPs are highly dependent on inciting stimulus, tissue site, and disease stage, amongst others. To this end, any therapeutic targeting metalloproteinases should be tailored to take these factors into account. Despite the challenges, there remains considerable potential in targeting specific MMP functions as part of a combinatorial treatment regime to target the inflammatory and/or tissue remodeling phases in fibrotic disease, improving the lives of thousands of patients each year.

\section{AUTHOR CONTRIBUTIONS}

EL drafted and wrote the manuscript and figures. MB and JM provided guidance, editing, and support with the manuscript. All authors provided conceptual input and reviewed the final manuscript.

\section{FUNDING}

EL is the recipient of a DMRF-I3V graduate studentship funded by Dalhousie Medical Research Foundation. This work is supported by the Canadian Institutes of Health Research Grant \#THC135230.

Andersen, G. N., Nilsson, K., Pourazar, J., Hackett, T. L., Kazzam, E., Blomberg, A., et al. (2007). Bronchoalveolar matrix metalloproteinase 9 relates to restrictive lung function impairment in systemic sclerosis. Respir. Med. 101, 2199-2206. doi: 10.1016/j.rmed.2007.04.019

Angiolilli, C., Marut, W., van der Kroef, M., Chouri, E., Reedquist, K. A., and Radstake, T. R. D. J. (2018). New insights into the genetics and epigenetics of systemic sclerosis. Nat. Rev. Rheumatol. 14, 657-673.

Annes, J. P., Chen, Y., Munger, J. S., and Rifkin, D. B. (2004). Integrin $\alpha v \beta 6-$ mediated activation of latent TGF- $\beta$ requires the latent TGF- $\beta$ binding protein1. J. Cell Biol. 165, 723-734. doi: 10.1083/jcb.200312172

Annes, J. P., Munger, J. S., and Rifkin, D. B. (2003). Making sense of latent TGF $\beta$ activation. J. Cell Sci. 116, 217-224. doi: 10.1242/jcs.00229

Asano, Y., Ihn, H., Kubo, M., Jinnin, M., Mimura, Y., Ashida, R., et al. (2006a). Clinical significance of serum levels of matrix metalloproteinase-13 in patients with systemic sclerosis. Rheumatology 45, 303-307. doi: 10.1093/rheumatology/ kei143

Asano, Y., Ihn, H., Kubo, M., Jinnin, M., Mimura, Y., Ashida, R., et al. (2006b). Clinical significance of serum matrix metalloproteinase-13 levels in patients with localized scleroderma. Clin. Exp. Rheumatol. 24, 394-399. 
Assassi, S., Radstake, T. R. D. J., Mayes, M. D., and Martin, J. (2013). Genetics of scleroderma: implications for personalized medicine? BMC Med. 11:9. doi: 10.1186/1741-7015-11-9

Bailey, J. R., Bland, P. W., Tarlton, J. F., Peters, I., Moorghen, M., Sylvester, P. A., et al. (2012). IL-13 promotes collagen accumulation in Crohn's disease fibrosis by down-regulation of fibroblast MMP synthesis: a role for innate lymphoid cells? PLoS One 7:e52332. doi: 10.1371/journal.pone.0052332

Bergman, M. R., Teerlink, J. R., Mahimkar, R., Li, L., Zhu, B.-Q., Nguyen, A., et al. (2007). Cardiac matrix metalloproteinase-2 expression independently induces marked ventricular remodeling and systolic dysfunction. Am. J. Physiol. Hear. Circ. Physiol. 292, 1847-1860.

Beyer, C., Schett, G., Gay, S., Distler, O., and Distler, J. H. W. (2009). Hypoxia. Hypoxia in the pathogenesis of systemic sclerosis. Arthritis Res. Ther. 11:220. doi: $10.1186 / \operatorname{ar} 2598$

Brew, K., and Nagase, H. (2010). The tissue inhibitors of metalloproteinases (TIMPs): an ancient family with structural and functional diversity. Biochim. Biophys. Acta Mol. Cell Res. 1803, 55-71. doi: 10.1016/j.bbamcr.2010.01.003

Brissett, M., Veraldi, K. L., Pilewski, J. M., Medsger, T. A., and Feghali-Bostwick, C. A. (2012). Localized expression of tenascin in systemic sclerosis-associated pulmonary fibrosis and its regulation by insulin-like growth factor binding protein 3. Arthritis Rheum. 64, 272-280. doi: 10.1002/art.30647

Brown, M., Postlethwaite, A. E., Myers, L. K., and Hasty, K. A. (2012). Supernatants from culture of type i collagen-stimulated PBMC from patients with cutaneous systemic sclerosis versus localized scleroderma demonstrate suppression of MMP-1 by fibroblasts. Clin. Rheumatol. 31, 973-981. doi: 10.1007/s10067-0121962-z

Burgstaller, G., Oehrle, B., Gerckens, M., White, E. S., Schiller, H. B., and Eickelberg, O. (2017). The instructive extracellular matrix of the lung: basic composition and alterations in chronic lung disease. Eur. Respir. J. 50:1601805. doi: 10.1183/ 13993003.01805-2016

Cabrera, S., Gaxiola, M., Arreola, J. L., Ramírez, R., Jara, P., D’Armiento, J., et al. (2007). Overexpression of MMP9 in macrophages attenuates pulmonary fibrosis induced by bleomycin. Int. J. Biochem. Cell Biol. 39, 2324-2338. doi: 10.1016/j.biocel.2007.06.022

Cabrera, S., Maciel, M., Hernández-Barrientos, D., Calyeca, J., Gaxiola, M., Selman, M., et al. (2019). Delayed resolution of bleomycin-induced pulmonary fibrosis in absence of MMP13 (collagenase 3). J. Physiol. Lung Cell. Mol. Physiol. 316, 961-976.

Caley, M. P., Martins, V. L. C., and O'Toole, E. A. (2015). Metalloproteinases and wound healing. Adv. Wound Care 4, 225-234. doi: 10.1089/wound.2014.0581

Chrabaszcz, M., Małyszko, J., Sikora, M., Alda-Malicka, R., Stochmal, A., Matuszkiewicz-Rowinska, J., et al. (2020). Renal involvement in systemic sclerosis: an update. Kidney Blood Press. Res. 45, 532-548.

Chuang, H. M., Chen, Y. S., and Harn, H. J. (2019). The versatile role of matrix metalloproteinase for the diverse results of fibrosis treatment. Molecules 24:4188. doi: 10.3390/molecules 24224188

Ciechomska, M., O’Reilly, S., Suwara, M., Bogunia-Kubik, K., and Van Laar, J. M. (2014). MiR-29a reduces TIMP-1 production by dermal fibroblasts via targeting TGF- $\beta$ activated kinase 1 binding protein 1, implications for systemic sclerosis. PLoS One 9:e115596. doi: 10.1371/journal.pone.0115596

Corpechot, C. (2002). Hypoxia-induced VEGF and collagen I expressions are associated with angiogenesis and fibrogenesis in experimental cirrhosis. Hepatology 35, 1010-1021. doi: 10.1053/jhep.2002.32524

Cottin, V., and Brown, K. K. (2019). Interstitial lung disease associated with systemic sclerosis (SSc-ILD). Respir. Res. 20:13.

Craig, V. J., Polverino, F., Laucho-Contreras, M. E., Shi, Y., Liu, Y., Osorio, J. C., et al. (2014). Mononuclear phagocytes and airway epithelial cells: novel sources of matrix metalloproteinase-8 (MMP-8) in patients with idiopathic pulmonary fibrosis. PLoS One 9:e97485. doi: 10.1371/journal.pone.0097485

Craig, V. J., Quintero, P. A., Fyfe, S. E., Patel, A. S., Knolle, M. D., Kobzik, L., et al. (2013). Profibrotic activities for matrix metalloproteinase-8 during bleomycinmediated lung injury. J. Immunol. 190, 4283-4296. doi: 10.4049/jimmunol. 1201043

Dancer, R. C. A., Wood, A. M., and Thickett, D. R. (2011). Metalloproteinases in idiopathic pulmonary fibrosis. Eur. Respir. J. 38, 1461-1467.

Daoussis, D., and Liossis, S.-N. (2019). Treatment of systemic sclerosis associated fibrotic manifestations: current options and future directions. Mediterr. J. Rheumatol. 30, 33-37. doi: 10.31138/mjr.30.1.33 de Meijer, V. E., Sverdlov, D. Y., Popov, Y., Le, H. D., Meisel, J. A., Nosé, V., et al. (2010). Broad-spectrum matrix metalloproteinase inhibition curbs inflammation and liver injury but aggravates experimental liver fibrosis in mice. PLoS One 5:e11256. doi: 10.1371/journal.pone.0011256

Dupont, S. (2019). Regulation of YAP/TAZ activity by mechanical cues: an experimental overview. Methods Mol. Biol. 1893, 183-202. doi: 10.1007/9781-4939-8910-2_15

Dupont, S., Morsut, L., Aragona, M., Enzo, E., Giulitti, S., Cordenonsi, M., et al. (2011). Role of YAP/TAZ in mechanotransduction. Nature 474, 179-184.

Fields, G. B. (2019). The rebirth of matrix metalloproteinase inhibitors: moving beyond the dogma. Cells 8:984. doi: 10.3390/cells8090984

Foronjy, R. F., Sun, J., Lemaitre, V., and d'Armiento, J. M. (2008). Transgenic expression of matrix metalloproteinase-1 inhibits myocardial fibrosis and prevents the transition to heart failure in a pressure overload mouse model. Hypertens. Res. 31, 725-735. doi: 10.1291/hypres.31.725

Frost, J., Ramsay, M., Mia, R., Moosa, L., Musenge, E., and Tikly, M. (2012). Differential gene expression of MMP-1, TIMP-1 and HGF in clinically involved and uninvolved skin in South Africans with SSc. Rheumatology 51, 1049-1052. doi: 10.1093/rheumatology/ker367

Fujishima, S., Shiomi, T., Yamashita, S., Yogo, Y., Nakano, Y., Inoue, T., et al. (2010). Production and activation of matrix metalloproteinase 7 (matrilysin 1) in the lungs of patients with idiopathic pulmonary fibrosis. Arch. Pathol. Lab. Med. 134, 1136-1142. doi: 10.5858/2009-0144-oa.1

Gaffney, J., Solomonov, I., Zehorai, E., and Sagi, I. (2015). Multilevel regulation of matrix metalloproteinases in tissue homeostasis indicates their molecular specificity in vivo. Matrix Biol. 44-46, 191-199. doi: 10.1016/j.matbio.2015.01. 012

García-Prieto, E., González-López, A., Cabrera, S., Astudillo, A., GutiérrezFernández, A., and Fanjul-Fernandez, M. (2010). Resistance to bleomycininduced lung fibrosis in MMP-8 deficient mice is mediated by interleukin-10. PLoS One 5:e13242. doi: 10.1371/journal.pone.0013242

Giannandrea, M., and Parks, W. C. (2014). Diverse functions of matrix metalloproteinases during fibrosis. DMM Dis. Model. Mech. 7, 193-203. doi: $10.1242 / \mathrm{dmm} .012062$

Heljasvaara, R., Nyberg, P., Luostarinen, J., Parikka, M., Heikkilä, P., Rehn, M., et al. (2005). Generation of biologically active endostatin fragments from human collagen XVIII by distinct matrix metalloproteases. Exp. Cell Res. 307, 292-304. doi: 10.1016/j.yexcr.2005.03.021

Henry, M. T., McMahon, K., Mackarel, A. J., Prikk, K., Sorsa, T., Maisi, P., et al. (2002). Matrix metalloproteinases and tissue inhibitor of metalloproteinase-1 in sarcoidosis and IPF. Eur. Respir. J. 20, 1220-1227. doi: 10.1183/09031936.02. 00022302

Herrera, J., Henke, C. A., and Bitterman, P. B. (2018). Extracellular matrix as a driver of progressive fibrosis. J. Clin. Invest. 128, 45-53. doi: 10.1172/jci93557

Herzog, E. L., Mathur, A., Tager, A. M., Feghali-Bostwick, C., Schneider, F., and Varga, J. (2014). Interstitial lung disease associated with systemic sclerosis and idiopathic pulmonary fibrosis: how similar and distinct? Arthritis Rheumatol. 66, 1967-1978. doi: 10.1002/art.38702

Holmbeck, K., Bianco, P., Caterina, J., Yamada, S., Kromer, M., Kuznetsov, S. A., et al. (1999). MT1-MMP-deficient mice develop dwarfism, osteopenia, arthritis, and connective tissue disease due to inadequate collagen turnover. Cell 99, 81-92. doi: 10.1016/s0092-8674(00)80064-1

Jiang, D., Liang, J., Campanella, G. S., Guo, R., Yu, S., Xie, T., et al. (2010). Inhibition of pulmonary fibrosis in mice by CXCL10 requires glycosaminoglycan binding and syndecan-4. J. Clin. Invest. 120, 2049-2057. doi: $10.1172 /$ jci38644

Kähäri, V. M., and Saarialho-Kere, U. (1997). Matrix metalloproteinases in skin. Exp. Dermatol. 6, 199-213. doi: 10.1016/b978-012545090-4/50009-4

Ke, B., Fan, C., Yang, L., and Fang, X. (2017). Matrix metalloproteinases-7 and kidney fibrosis. Front. Physiol. 8:21. doi: 10.3389/fphys.2017.00021

Khanna, D., Tashkin, D. P., Denton, C. P., Lubell, M. W., Vazquez-Mateo, C., and Wax, S. (2019). Ongoing clinical trials and treatment options for patients with systemic sclerosis-associated interstitial lung disease. Rheumatology (U. K.) 58, 567-579. doi: 10.1093/rheumatology/key151

Kikuchi, K., Kadono, T., Furue, M., and Tamaki, K. (1997). Tissue inhibitor of metalloproteinase 1 (TIMP-1) may be an autocrine growth factor in scleroderrn.a fibroblasts. J. Invest. Dermatol. 108, 281-284. doi: 10.1111/15231747.ep12286457 
Kim, W. U., Min, S. Y., Cho, M. L., Hong, K. H., Shin, Y. J., Park, S. H., et al. (2005). Elevated matrix metalloproteinase-9 in patients with systemic sclerosis. Arthritis Res. Ther. 7:R71.

Kobayashi, T., Kim, H. J., Liu, X., Sugiura, H., Kohyama, T., Fang, Q., et al. (2014). Matrix metalloproteinase- 9 activates TGF- $\beta$ and stimulates fibroblast contraction of collagen gels. Am. J. Physiol. Lung Cell. Mol. Physiol. 306:L1006.

Kowal-Bielecka, O., Fransen, J., Avouac, J., Becker, M., Kulak, A., Allanore, Y., et al. (2017). Update of EULAR recommendations for the treatment of systemic sclerosis. Ann. Rheum. Dis. 76, 1327-1339.

Lagares, D., Santos, A., Grasberger, P. E., Liu, F., Probst, C. K., Rahimi, R. A., et al. (2017). Targeted apoptosis of myofibroblasts with the BH3 mimetic ABT263 reverses established fibrosis. Sci. Transl. Med. 9:eaal3765. doi: 10.1126/ scitranslmed.aal3765

Lambova, S. (2014). Cardiac manifestations in systemic sclerosis. World J. Cardiol. 6:993. doi: 10.4330/wjc.v6.i9.993

Lampi, M. C., and Reinhart-King, C. A. (2018). Targeting extracellular matrix stiffness to attenuate disease: from molecular mechanisms to clinical trials. Sci. Transl. Med. 10:eaao0475. doi: 10.1126/scitranslmed.aao0475

Li, L., and Li, H. (2013). Role of microRNA-mediated MMP regulation in the treatment and diagnosis of malignant tumors. Cancer Biol. Ther. 14:796. doi: $10.4161 /$ cbt.25936

Li, Q., Park, P. W., Wilson, C. L., and Parks, W. C. (2002). Matrilysin shedding of syndecan-1 regulates chemokine mobilization and transepithelial efflux of neutrophils in acute lung injury. Cell 111, 635-646. doi: 10.1016/s00928674(02)01079-6

Liu, F., Mih, J. D., Shea, B. S., Kho, A. T., Sharif, A. S., Tager, A. M., et al. (2010). Feedback amplification of fibrosis through matrix stiffening and COX-2 suppression. J. Cell Biol. 190, 693-706. doi: 10.1083/jcb.201004082

Loffek, S., Schilling, O., and Franzke, C.-W. (2011). Biological role of matrix metalloproteinases: a critical balance. Eur. Respir. J. 38, 191-208. doi: 10.1183/ 09031936.00146510

Madala, S. K., Pesce, J. T., Ramalingam, T. R., Wilson, M. S., Minnicozzi, S., Cheever, A. W., et al. (2010). Matrix metalloproteinase 12-deficiency augments extracellular matrix degrading metalloproteinases and attenuates IL13-dependent fibrosis. J. Immunol. 184, 3955-3963. doi: 10.4049/jimmunol. 0903008

Manetti, M., Guiducci, S., Romano, E., Bellando-Randone, S., Conforti, M. L., IbbaManneschi, L., et al. (2012). Increased serum levels and tissue expression of matrix metalloproteinase- 12 in patients with systemic sclerosis: correlation with severity of skin and pulmonary fibrosis and vascular damage. Ann. Rheum. Dis. 71, 1064-1072. doi: 10.1136/annrheumdis-2011-200837

Manetti, M., Ibba-Manneschi, L., Fatini, C., Guiducci, S., Cuomo, G., Bonino, C., et al. (2010). Association of a functional polymorphism in the matrix metalloproteinase-12 promoter region with systemic sclerosis in an Italian population. J. Rheumatol. 37, 1852-1857. doi: 10.3899/jrheum.100237

Manicone, A. M., Huizar, I., and McGuire, J. K. (2009). Matrilysin (matrix metalloproteinase-7) regulates anti-inflammatory and antifibrotic pulmonary dendritic cells that express CD103 ( $\alpha$ E $\beta 7$-integrin). Am. J. Pathol. 175, 23192331. doi: 10.2353/ajpath.2009.090101

Marie Burdick, S. D., Xu, Z. J., Xue, Y. Y., Keane, M. P., Strieter, R. M., Belperio, J. A., et al. (1999). IFN- $\gamma$-inducible protein-10 attenuates bleomycin-induced pulmonary fibrosis via inhibition of angiogenesis. J. Immunol. 163, 5686-5692.

Martin, P., Teodoro, W. R., Velosa, A. P. P., de Morais, J., Carrasco, S., Christmann, R. B., et al. (2012). Abnormal collagen V deposition in dermis correlates with skin thickening and disease activity in systemic sclerosis. Autoimmun. Rev. 11, 827-835. doi: 10.1016/j.autrev.2012.02.017

McFarlane, I. M., Bhamra, M. S., Kreps, A., Iqbal, S., Al-Ani, F., SaladiniAponte, C., et al. (2018). Gastrointestinal manifestations of systemic sclerosis. Rheumatology (Sunnyvale) 8:235.

Medina, C., and Radomski, M. W. (2006). Role of matrix metalloproteinases in intestinal inflammation. J. Pharmacol. Exp. Ther. 318, 933-938. doi: 10.1124/ jpet.106.103465

Mohan, V., Talmi-Frank, D., Arkadash, V., Papo, N., and Sagi, I. (2016). Matrix metalloproteinase protein inhibitors: highlighting a new beginning for metalloproteinases in medicine. Metalloproteinases Med. 3, 31-47. doi: 10. 2147/mnm.s65143

Moinzadeh, P., Krieg, T., Hellmich, M., Brinckmann, J., Neumann, E., MüllerLadner, U., et al. (2011). Elevated MMP-7 levels in patients with systemic sclerosis: correlation with pulmonary involvement. Exp. Dermatol. 20, 770-773. doi: 10.1111/j.1600-0625.2011.01321.x

Mora, G. F. (2009). Systemic sclerosis: environmental factors. J. Rheumatol. 36, 2383-2396. doi: 10.3899/jrheum.090207

Nagase, H., Visse, R., and Murphy, G. (2006). Structure and function of matrix metalloproteinases and TIMPs. Cardiovasc. Res. 69, 562-573. doi: 10.1016/j. cardiores.2005.12.002

Nguyen, T. T., Mobashery, S., and Chang, M. (2016). "Roles of matrix metalloproteinases in cutaneous wound healing," in Wound Healing-New insights into Ancient Challenges, ed. V. A. Alexandrescu (London: IntechOpen).

Nishijima, C., Hayakawa, I., Matsushita, T., Komura, K., Hasegawa, M., Takehara, K., et al. (2004). Autoantibody against matrix metalloproteinase- 3 in patients with systemic sclerosis. Clin. Exp. Immunol. 138, 357-363. doi: 10.1111/j.13652249.2004.02615.x

Niwa, H., Kanno, Y., Shu, E., and Seishima, M. (2020). Decrease in matrix metalloproteinase-3 activity in systemic sclerosis fibroblasts causes $\alpha 2$ antiplasmin and extracellular matrix deposition, and contributes to fibrosis development. Mol. Med. Rep. 22, 3001-3007.

Nkyimbeng, T., Ruppert, C., Shiomi, T., Dahal, B., Lang, G., Seeger, W., et al. (2013). Pivotal role of matrix metalloproteinase 13 in extracellular matrix turnover in idiopathic pulmonary fibrosis. PLoS One 8:e73279. doi: 10.1371/ journal.pone.0073279

Orphanides, C., Fine, L. G., and Norman, J. T. (1997). Hypoxia stimulates proximal tubular cell matrix production via a TGF- $\beta 1$-independent mechanism. Kidney Int. 52, 637-647. doi: 10.1038/ki.1997.377

O’Sullivan, S., Gilmer, J. F., and Medina, C. (2015). Matrix metalloproteinases in inflammatory bowel disease: an update. Mediators Inflamm. 2015:964131.

Pardo, A., and Selman, M. (2006). Matrix metalloproteases in aberrant fibrotic tissue remodeling. Proc. Am. Thorac. Soc. 3, 383-388. doi: 10.1513/pats.200601$012 \mathrm{tk}$

Parker, M. W., Rossi, D., Peterson, M., Smith, K., Sikstrom, K., White, E. S., et al. (2014). Fibrotic extracellular matrix activates a profibrotic positive feedback loop. J. Clin. Invest. 124, 1622-1635. doi: 10.1172/jci71386

Pomianowska, E., Sandnes, D., Grzyb, K., Schjølberg, A. R., Aasrum, M., Tveteraas, I. H., et al. (2014). Inhibitory effects of prostaglandin E2 on collagen synthesis and cell proliferation in human stellate cells from pancreatic head adenocarcinoma. BMC Cancer 14:413. doi: 10.1186/1471-2407-14-413

Pushpakumar, S., Kundu, S., Pryor, T., Givvimani, S., Lederer, E., Tyagi, S. C., et al. (2013). Angiotensin-II induced hypertension and renovascular remodelling in tissue inhibitor of metalloproteinase 2 knockout mice. J. Hypertens. 31, 2270-2281. doi: 10.1097/hjh.0b013e3283649b33

Ramos, P. S., Silver, R. M., and Feghali-Bostwick, C. A. (2015). Genetics of systemic sclerosis. Curr. Opin. Rheumatol. 27, 521-529.

Richter, A. G., McKeown, S., Rathinam, S., Harper, L., Rajesh, P., McAuley, D. F., et al. (2009). Soluble endostatin is a novel inhibitor of epithelial repair in idiopathic pulmonary fibrosis. Thorax 64, 156-161. doi: 10.1136/thx.2008. 102814

Sallam, H., McNearney, T. A., and Chen, J. D. Z. (2006). Systematic review: pathophysiology and management of gastrointestinal dysmotility in systemic sclerosis (scleroderma). Aliment. Pharmacol. Ther. 23, 691-712. doi: 10.1111/j. 1365-2036.2006.02804.x

Santos, A., and Lagares, D. (2018). Matrix stiffness: the conductor of organ fibrosis. Curr. Rheumatol. Rep. 20:2.

Sen, A. I., Shiomi, T., Okada, Y., and D'Armiento, J. M. (2010). Deficiency of matrix metalloproteinase-13 increases inflammation after acute lung injury. Exp. Lung Res. 36, 615-624. doi: 10.3109/01902148.2010.497201

Shimada, S., Makino, K., Jinnin, M., Sawamura, S., Kawano, Y., Ide, M., et al. (2020). CXCL17-mediated downregulation of type I collagen via MMP1 and miR-29 in skin fibroblasts possibly contributes to the fibrosis in systemic sclerosis. J. Dermatol. Sci. 100, 183-191. doi: 10.1016/j.jdermsci.2020.09.010

Sing, T., Jinnin, M., Yamane, K., Honda, N., Makino, K., Kajihara, I., et al. (2012). MicroRNA-92a expression in the sera and dermal fibroblasts increases in patients with scleroderma. Rheumatology (U. K.) 51, 1550-1556. doi: 10. 1093/rheumatology/kes120

Sobolewski, P., Maślińska, M., Wieczorek, M., Łagun, Z., Malewska, A., Roszkiewicz, M., et al. (2019). Systemic sclerosis-multidisciplinary disease: clinical features and treatment. Reumatologia 57, 221-233. doi: 10.5114/reum. 2019.87619 
Solini, A., Rossi, C., Santini, E., Madec, S., Salvati, A., and Ferrannini, E. (2011). Angiotensin-II and rosuvastatin influence matrix remodeling in human mesangial cells via metalloproteinase modulation. J. Hypertens. 29, 1930-1939. doi: 10.1097/hjh.0b013e32834abceb

Stawski, L., Haines, P., Fine, A., Rudnicka, L., and Trojanowska, M. (2014). MMP-12 deficiency attenuates angiotensin II-induced vascular injury, M2 macrophage accumulation, and skin and heart fibrosis. PLoS One 9:e109763. doi: 10.1371/journal.pone.0109763

Steen, V. D. (2014). Kidney involvement in systemic sclerosis. Press. Med. 43, e305-e314.

Stijn, W., Verleden Stijn, E., Vanaudenaerde Bart, M., Marijke, W., Christophe, D., Jonas, Y., et al. (2013). Multiplex protein profiling of bronchoalveolar lavage in idiopathic pulmonary fibrosis and hypersensitivity pneumonitis. Ann. Thorac. Med. 8, 38-45. doi: 10.4103/1817-1737.105718

Stock, C., De Lauretis, A., Visca, D., Daccord, C., Kokosi, M., Alfieri, V., et al. (2019). Serum biomarkers in SSc-ILD: association with presence, severity and prognosis. Eur. Respir. J. 54:A5198.

Sunderkötter, C., and Riemekasten, G. (2006). Pathophysiology and clinical consequences of Raynaud's phenomenon related to systemic sclerosis. Rheumatology 45 (Suppl. 3), iii33-iii35.

Tager, A. M., Kradin, R. L., Lacamera, P., Bercury, S. D., Campanella, G. S. V., Leary, C. P., et al. (2004). Inhibition of pulmonary fibrosis by the chemokine IP-10/CXCL10. Am. J. Respir. Cell Mol. Biol. 31, 395-404. doi: 10.1165/rcmb. 2004-0175oc

Toriseva, M. J., Ala-Aho, R., Karvinen, J., Baker, A. H., Marjomäki, V. S., Heino, J., et al. (2007). Collagenase-3 (MMP-13) enhances remodeling of threedimensional collagen and promotes survival of human skin fibroblasts. J. Invest. Dermatol. 127, 49-59. doi: 10.1038/sj.jid.5700500

Tschumperlin, D. J., Ligresti, G., Hilscher, M. B., and Shah, V. H. (2018). Mechanosensing and fibrosis. J. Clin. Invest. 128, 74-84. doi: 10.1172/jci93561

Tzelepis, G. E., Kelekis, N. L., Plastiras, S. C., Mitseas, P., Economopoulos, N., Kampolis, C., et al. (2007). Pattern and distribution of myocardial fibrosis in systemic sclerosis: a delayed enhanced magnetic resonance imaging study. Arthritis Rheum. 56, 3827-3836. doi: 10.1002/art.22971

Valentinis, B., Bhala, A., DeAngelis, T., Baserga, R., and Cohen, P. (1995). The human insulin-like growth factor (IGF) binding protein-3 inhibits the growth of fibroblasts with a targeted disruption of the IGF-I receptor gene. Mol. Endocrinol. 9, 361-367. doi: 10.1210/me.9.3.361

Van Caam, A., Vonk, M., Van Den Hoogen, F., Van Lent, P., and Van Der Kraan, P. (2018). Unraveling SSc pathophysiology: the myofibroblast. Front. Immunol. 9:2452. doi: 10.3389/fimmu.2018.02452

Van Den Steen, P. E., Dubois, B., Nelissen, I., Rudd, P. M., Dwek, R. A., and Opdenakker, G. (2002). Biochemistry and molecular biology of gelatinase B or matrix metalloproteinase-9 (MMP-9). Crit. Rev. Biochem. Mol. Biol. 37, 375-536. doi: 10.1080/10409230290771546

Vandenbroucke, R. E., and Libert, C. (2014). Is there new hope for therapeutic matrix metalloproteinase inhibition? Nat. Rev. Drug Discov. 13, 904-927. doi: $10.1038 / \mathrm{nrd} 4390$

Varga, J., and Abraham, D. (2007). Systemic sclerosis: a prototypic multisystem fibrotic disorder. J. Clin. Invest. 117, 557-567. doi: 10.1172/jci31139

Varga, J., and Bashey, R. I. (1995). Regulation of connective tissue synthesis in systemic sclerosis. Int. Rev. Immunol. 12, 187-199. doi: 10.3109/ 08830189509056712

Varga, J., Trojanowska, M., and Kuwana, M. (2017). Pathogenesis of systemic sclerosis: recent insights of molecular and cellular mechanisms and therapeutic opportunities. J. Scleroderma Relat. Disord. 2, 137-152. doi: 10.5301/jsrd. 5000249

Wang, Y., Fan, P.-S., and Kahaleh, B. (2006). Association between enhanced type I collagen expression and epigenetic repression of theFLI1 gene in scleroderma fibroblasts. Arthritis Rheum. 54, 2271-2279. doi: 10.1002/art.21948

Waszczykowska, A., Podgórski, M., Waszczykowski, M., Gerlicz-Kowalczuk, Z., and Jurowski, P. (2020). Matrix metalloproteinases MMP-2 and MMP-9, their inhibitors TIMP-1 and TIMP-2, vascular endothelial growth factor and sVEGFR-2 as predictive markers of ischemic retinopathy in patients with systemic sclerosis-case series report. Int. J. Mol. Sci. 21:8703. doi: 10.3390/ ijms21228703

Wilborn, J., Crofford, L. J., Burdick, M. D., Kunkel, S. L., Strieter, R. M., and Peters-Golden, M. (1995). Cultured lung fibroblasts isolated from patients with idiopathic pulmonary fibrosis have a diminished capacity to synthesize prostaglandin E2 and to express cyclooxygenase-2. J. Clin. Invest. 95, 18611868. doi: $10.1172 /$ jci117866

Wipff, P. J., Rifkin, D. B., Meister, J. J., and Hinz, B. (2007). Myofibroblast contraction activates latent TGF- $\beta 1$ from the extracellular matrix. J. Cell Biol. 179, 1311-1323. doi: 10.1083/jcb.200704042

Xu, X., Zheng, L., Yuan, Q., Zhen, G., Crane, J. L., Zhou, X., et al. (2018). Transforming growth factor- $\beta$ in stem cells and tissue homeostasis. Bone Res. $6: 2$.

Yamamoto, T., Takagawa, S., Katayama, I., Yamazaki, K., Hamazaki, Y., Shinkai, H., et al. (1999). Animal model of sclerotic skin. I: local injections of bleomycin induce sclerotic skin mimicking scleroderma. J. Invest. Dermatol. 112, 456-462. doi: 10.1046/j.1523-1747.1999.00528.x

Yamashita, C. M., Dolgonos, L., Zemans, R. L., Young, S. K., Robertson, J., Briones, N., et al. (2011). Matrix metalloproteinase 3 is a mediator of pulmonary fibrosis. Am. J. Pathol. 179, 1733-1745.

Yu, G., Kovkarova-Naumovski, E., Jara, P., Parwani, A., Kass, D., Ruiz, V., et al. (2012). Matrix metalloproteinase-19 is a key regulator of lung fibrosis in mice and humans. Am. J. Respir. Crit. Care Med. 186, 752-762. doi: 10.1164/rccm. 201202-0302oc

Yu, Q., and Stamenkovic, I. (2000). Cell surface-localized matrix metalloproteinase-9 proteolytically activates TGF-and promotes tumor invasion and angiogenesis. Genes Dev. 14, 163-176.

Zakiyanov, O., Kalousová, M., Zima, T., and Tesař, V. (2019). Matrix metalloproteinases in renal diseases: a critical appraisal. Kidney Blood Press. Res. 44, 298-330. doi: 10.1159/000499876

Zhao, J., Shu, B., Chen, L., Tang, J., Zhang, L., Xie, J., et al. (2016). Prostaglandin E2 inhibits collagen synthesis in dermal fibroblasts and prevents hypertrophic scar formation in vivo. Exp. Dermatol. 25, 604-610. doi: 10.1111/exd.13014

Zhou, B., Zhu, H., Luo, H., Gao, S., Dai, X., Li, Y., et al. (2017). MicroRNA-202-3p regulates scleroderma fibrosis by targeting matrix metalloproteinase 1 . Biomed. Pharmacother. 87, 412-418. doi: 10.1016/j.biopha.2016.12.080

Zigrino, P., Brinckmann, J., Niehoff, A., Lu, Y., Giebeler, N., Eckes, B., et al. (2016). Fibroblast-derived MMP-14 regulates collagen homeostasis in adult skin. J. Invest. Dermatol. 136, 1575-1583. doi: 10.1016/j.jid.2016.03.036

Zuo, F., Kaminski, N., Eugui, E., Allard, J., Yakhini, Z., Ben-Dor, A., et al. (2002). Gene expression analysis reveals matrilysin as a key regulator of pulmonary fibrosis in mice and humans. Proc. Natl. Acad. Sci. U.S.A. 99, 6292-6297. doi: 10.1073/pnas.092134099

Conflict of Interest: The authors declare that the research was conducted in the absence of any commercial or financial relationships that could be construed as a potential conflict of interest.

Publisher's Note: All claims expressed in this article are solely those of the authors and do not necessarily represent those of their affiliated organizations, or those of the publisher, the editors and the reviewers. Any product that may be evaluated in this article, or claim that may be made by its manufacturer, is not guaranteed or endorsed by the publisher.

Copyright (c) 2021 Leong, Bezuhly and Marshall. This is an open-access article distributed under the terms of the Creative Commons Attribution License (CC BY). The use, distribution or reproduction in other forums is permitted, provided the original author(s) and the copyright owner(s) are credited and that the original publication in this journal is cited, in accordance with accepted academic practice. No use, distribution or reproduction is permitted which does not comply with these terms. 